\title{
Low Modulation Bias InGaN-based Integrated EA- Modulator-Laser on Semipolar GaN Substrate
}

\author{
Chao Shen $^{1}$, John T. Leonard ${ }^{2}$, Arash Pourhashemi ${ }^{2}$, Hassan Oubei ${ }^{1}$, Mohd Sharizal Alias ${ }^{1}$, Tien \\ Khee $\mathrm{Ng}^{1}$, Shuji Nakamura ${ }^{2}$, Steven P. DenBaars ${ }^{2}$, James S. Speck ${ }^{2}$, Ahmed Y. Alyamani ${ }^{3}$, Munir \\ M. Eldesouki ${ }^{3}$ and Boon S. Ooi ${ }^{1 *}$ \\ ${ }^{1}$ Photonics Laboratory, King Abdullah University of Science and Technology, Thuwal 21534, Saudi Arabia \\ ${ }^{2}$ Materials Department, University of California Santa Barbara, Santa Barbara, CA 93106, USA \\ ${ }^{I}$ King Abdulaziz City for Science and Technology (KACST), Riyadh 11442, Saudi Arabia \\ *Corresponding E-mail: boon.ooi@kaust.edu.sa
}

\section{INTRODUCTION}

The development of InGaN based laser diodes (LDs) [1] for visible light communication [2] has recently attracted increasing attention. The common feature of the devices demonstrated so far has been the implementation of direct current modulation of laser diodes [3-5]. In this work, we reported an alternate modulation approach based on seamless, monolithic integration of optical modulator with laser diode. There are several potential benefits of this approach over the direct modulation of LDs: (1) suppression the deleterious transient heating [6]; (2) reduction of dissipated switching power [7]; and (3) smaller capacitance [8]. As the electroabsorptionmodulator (EAM) can be fabricated using the same InGaN/GaN quantum well (QW) structure as the laser diode, subsequent epitaxy regrowth is not required.

In this paper, we demonstrated the first blue-emitting integrated electroabsorption-modulator-laser (IML)

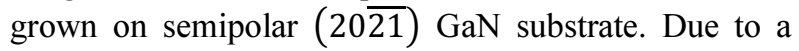
smaller polarization field in InGaN/GaN quantum-well device grown on semipolar substrate, we demonstrated that $0 \mathrm{~V} /-3.5 \mathrm{~V}$ modulation biases are sufficient for On/Off switching operation, which is half of the bias required for the modulator grown on c-plane substrate.

\section{EXPERIMENTS}

The InGaN/GaN QW based IML is a three-terminal device consisted of reverse-biased integrated modulator section and forward-biased gain section (see Fig. 1) grown using metalorganic chemical vapor deposition

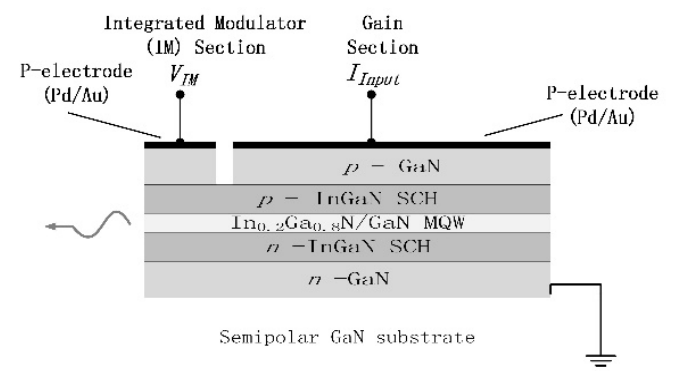

Fig. 1. Schematic diagram of integrated electroabsorptionmodulator-laser (IML) on semipolar (20ㄹ) GaN substrate.
(MOCVD). The IML is made of $2 \mu m$-wide ridge waveguide with $100 \mu \mathrm{m}$ integrated modulator (IM) and $1100 \mu \mathrm{m}$ gain sections. Both sections are optically coupled but electrically separated $(22 \mathrm{k} \Omega$ resistance between the two sections). The device was tested using Keithley 2520 diode laser testing system with calibrated Si photodetector and integrating sphere from Labsphere. The small signal modulation characteristics were measured using Agilent E8361C network analyzer and Menlo Systems APD 210 Si avalanche photodetector.

\section{RESULTS AND DISCUSSION}

Figure 2(a) shows the optical output power vs. the injection current in the gain region (L-I) characteristics for the IML under different bias voltage in the modulator section $\left(\mathrm{V}_{\mathrm{IM}}\right.$ from $0 \mathrm{~V}$ to $\left.-3.7 \mathrm{~V}\right)$. Without any modulation bias $\left(\mathrm{V}_{\mathrm{IM}}=0 \mathrm{~V}\right)$, the IML shows a threshold current of
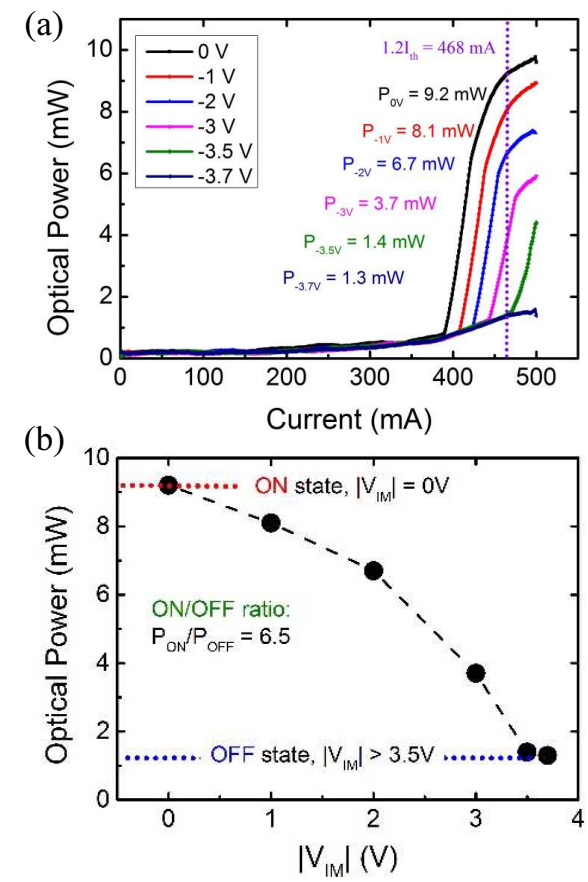

Fig. 2. Plot of: (a) optical power vs. injection current (L-I) of IML with varying bias voltage on IM. The optical power at $468 \mathrm{~mA}(1.2$ $\mathrm{I}_{\mathrm{th}}$ ) in the gain region is indicated, and (b) optical power at $468 \mathrm{~mA}$ $v$ s. the absolute modulation bias voltage, $\left|\mathrm{V}_{\mathrm{IM}}\right|$. 
$390 \mathrm{~mA}$. Further increase in injection current to $468 \mathrm{~mA}$ at the gain region $\left(\mathrm{I}_{\mathrm{LD}}=1.2 \mathrm{I}_{\mathrm{th}}\right)$ gave $9.2 \mathrm{~mW}$ optical output power under DC operation. The operating current was limited to $500 \mathrm{~mA}$ as the thermal roll-over became significant when $\mathrm{I}_{\mathrm{LD}}>500 \mathrm{~mA}$. As expected, a decreasing optical power and increasing lasing threshold current was achieved in the IML device with increasing $\left|\mathrm{V}_{\mathrm{IM}}\right|$. The optical power of IML at $\mathrm{I}_{\mathrm{LD}}=468 \mathrm{~mA}$ was $8.1 \mathrm{~mW}, 6.7$ $\mathrm{mW}, 3.7 \mathrm{~mW}$, and $1.4 \mathrm{~mW}$ at $\mathrm{V}_{\mathrm{IM}}=-1 \mathrm{~V},-2 \mathrm{~V},-3 \mathrm{~V}$, and $-3.5 \mathrm{~V}$, respectively. The strong $\mathrm{V}_{\mathrm{IM}}$-dependence in optical power is evident in Fig. 2(b), indicating the amplitude modulation effect. When $\left|\mathrm{V}_{\mathrm{IM}}\right|>3.5 \mathrm{~V}$, the lasing was suppressed at $\mathrm{I}_{\mathrm{LD}}=468 \mathrm{~mA}$, which representing the Off state. The IML has its maximum emission power at $\mathrm{V}_{\mathrm{IM}}=0 \mathrm{~V}$, which is the On state. At $\mathrm{I}_{\mathrm{LD}}$ $=468 \mathrm{~mA}$, the IML exhibited an On/Off ratio $\left(\mathrm{P}_{\mathrm{ON}} / \mathrm{P}_{\mathrm{OFF}}\right)$ of $6.5(\sim 8.1 \mathrm{~dB})$ with a relatively small bias of $0 /-3.5 \mathrm{~V}$, compared to $\sim 7 \mathrm{~V}$ required in c-plane modulators [7].

To study the electroabsorption response in semipolar (2021) InGaN/GaN QWs based integrated modulator, the modal absorption was measured using segmented contact method [9]. Figure 3 shows the changes in modal absorption with $\mathrm{V}_{\mathrm{IM}}$ varied from $-1 \mathrm{~V}$ to $-3.5 \mathrm{~V}$, which were calculated by subtracting the measured unbiased absorption spectrum from that of the biased absorption spectrum. The change is due to the applied external field on IM partially cancels the built-in polarization-induced electric fields in the active region, thereby increasing the absorption with increasing $\mathrm{V}_{\mathrm{IM}}$. The measured change in modal absorption at the IM section at $\mathrm{V}_{\mathrm{IM}}=-3.5 \mathrm{~V}$ is -27 $\mathrm{cm}^{-1}$, which corresponds to an absorption coefficient change of $\sim 600 \mathrm{~cm}^{-1}$ at the lasing wavelength. Thus, the significant change in absorption coefficient in IM region in response to modulation bias is effective for modulating the optical output power of IML.

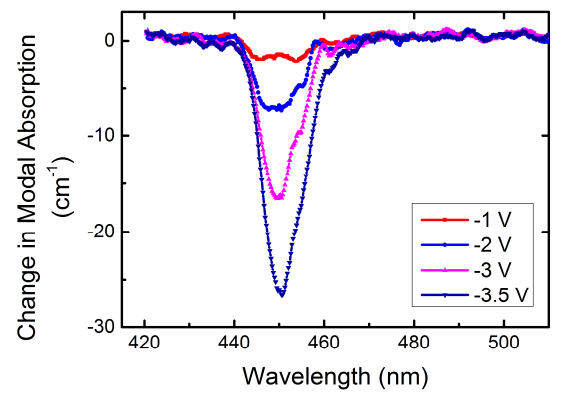

Fig. 3. Modal absorption spectra under different modulation bias voltages $\left(\mathrm{V}_{\mathrm{IM}}\right)$.

For a proof-of-concept demonstration of $\mathrm{AC}$ modulation, we performed the small signal modulation measurement by applying $-10 \mathrm{dBm} \mathrm{AC}$ signal to the integrated modulator while pumping the gain region with a constant driving current (470 mA). A $-3 \mathrm{~dB}$ bandwidth of $\sim 0.98 \mathrm{GHz}$ was measured in the IML with $\left|\mathrm{V}_{\mathrm{IM}}\right|=3 \mathrm{~V}$ (see Fig. 4). The frequency response is limited by the bandwidth of the photodetector. Nevertheless, our demonstration proves the feasibility of using IML for data transmission.

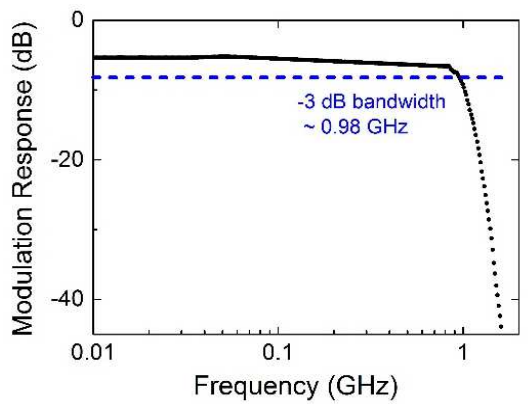

Fig. 4. Small signal modulation of IML under injection current of $470 \mathrm{~mA}$ and modulation bias voltage of $-3 \mathrm{~V}$.

\section{CONCLUSIONS}

In summary, we demonstrated the monolithic integration of electroabsorption modulator with laser diode and measured DC and AC modulation characteristics of the device, which is grown on (20) plane $\mathrm{GaN}$ substrate. By alternating the modulation voltage at $-3.5 \mathrm{~V}$ and $0 \mathrm{~V}$, we achieve the laser output power of $<1.5 \mathrm{~mW}$ to $>9 \mathrm{~mW}$, respectively, leading to $8.1 \mathrm{~dB}$ On/Off ratio. Our results clearly show that a low power consumption modulator can be achieved with semipolar EA-modulator compared to that of the c-plane devices.

\section{ACKNOWLEDGEMENT}

The support from KAUST baseline funding and King Abdulaziz City for Science and Technology (KACST) Technology Innovation Center for Solid State Lighting at KAUST are gratefully acknowledged.

\section{REFERENCES}

[1] A. Pourhashemi, R. M. Farrell, D. A. Cohen, J. S. Speck, S. P. DenBaars, and S. Nakamura, Applied Physics Letters 106 (11), $111105(2015)$

[2] Y.-C. Chi, D.-H. Hsieh, C.-T. Tsai, H.-Y. Chen, H.-C. Kuo, and G.-R. Lin, Optics Express 23 (10), 13051 (2015).

[3] D. Tsonev, S. Videv, and H. Haas, Optics Express 23 (2), 1627 (2015).

[4] C. T. Tsai, M. C. Cheng, Y. C. Chi, and G. R. Lin, IEEE Journal of Selected Topics in Quantum Electronics 21 (6), 1500313 (2015).

[5] Y.-C. Chi, C.-Y. Lin, M.-C. Cheng, C.-T. Tsai, and G.-R. Lin, Proceeding of Optical Fiber Communication Conference (OFC), Los Angeles 2015, p. Th1H.5 (2015).

[6] C. K. Kao, A. Bhattacharyya, C. Thomidis, R. Paiella, and T. D. Moustakas, Journal of Applied Physics 109 (8), 083102 (2011).

[7] M. Kneissl, T. L. Paoli, P. Kiesel, D. W. Treat, M. Teepe, N. Miyashita, et al., Applied Physics Letters, 80 (18), 3283-3285 (2002).

[8] E. Sari, T. Ozel, A. Koc, J. W. Ju, H. K. Ahn, I. H. Lee, et al., Applied Physics Letters, 92 (20), 201105 (2008).

[9] C. Shen, T. K. Ng, B. Janjua, A. Alyamani, M. M. El-Desouki, J. Speck, et al., Asia Communications and Photonics Conference (ACP), Shanghai 2014, p. AW4A.1 (2014). 